\title{
The home dialysis first paradigm: suitability and transitioning
}

\author{
Mark Benaroia · David C. Mendelssohn
}

Received: 28 May 2010/Accepted: 5 June 2010/Published online: 30 June 2010

(C) Springer Science+Business Media, B.V. 2010

Patients with progressive renal insufficiency are faced with a multitude of decisions and choices during the continuum of their care. Those that choose to embark on the road to renal replacement therapy are faced with complicated decisions regarding modality choice and possibly transplantation. Others may proceed with palliative pre-dialysis care, without considering any further therapy. Empowerment of patient choice or autonomy is now felt to be central to medical decision making [1]. It seems evident that in the past, many patients with end-stage renal disease (ESRD) have reported that they did not receive all the information required to make an informed choice about dialytic modalities [2].

Lameire and colleagues introduced an integrated care approach to modality decision making more than

\footnotetext{
M. Benaroia

Division of Nephrology, Grand River Hospital, 835 King Street, West, Kitchener, ON N2G 1G3, Canada

\section{Benaroia}

Department of Medicine, McMaster University, Hamilton, ON, Canada

D. C. Mendelssohn

University of Toronto, Toronto, ON, Canada

D. C. Mendelssohn ( $\square)$

Department of Nephrology, Humber River Regional

Hospital, Toronto, ON, Canada

e-mail: dmendelssohn@hrrh.on.ca
}

10 years ago [3]. Their approach was to intimately plan pre-dialysis care with timely referral to a renal multidisciplinary team, timely preparation for dialysis followed by timely initiation. Peritoneal dialysis (PD) was their focus of the initial modality of choice for suitable patients with timely transfer to in-center hemodialysis (HD) as a rescue therapy should PD be inadequate. Although this approach was a welcome one in regard to attempting to integrate or streamline pre-dialysis care, it had a number of shortcomings. Mendelssohn and Pierratos identified four important deficiencies with this approach including a lack of emphasis on the following: (1) decreasing the rate of progression of chronic kidney disease, (2) management of cardiovascular risk and other comorbidities, (3) consideration of home HD, pre-emptive transplant, and PD as the initial modality for suitable patients, and (4) empowerment of patient choice [4].

Mendelssohn and Pierratos indicated a number of reasons why home HD is a good initial modality [4]. The advantages listed in their 2001 editorial still hold today (and some are more robust with the supporting data that has accrued since then). Briefly, home HD has the following advantages: (1) improved extracellular fluid volume and blood pressure control, (2) liberalization of the diet, (3) patient independence and flexibility, (4) improved quality of life, (5) reduced erythropoietin-stimulating agent utilization, (6) possible survival benefits, (7) possibly comparable lifeexpectancy results as transplantation, and (8) more cost-effective than in-center HD (after approximately 
18 months). This list is not exhaustive but does outline some of the more important advantages of home HD.

Recently, Oreopoulous and colleagues have restated the reformulated integrated care model that home HD or PD can indeed be the first option modalities [5]. We are thankful to Oreopoulous and colleagues for publishing their comprehensive review because it highlights the shortcomings in the slow rate of dissemination of new knowledge in the nephrology literature in general. Important concepts that can possibly improve physiology, morbidity, mortality, and patient quality of life while reducing overall costs may never make it to administrators or decision makers in a timely fashion. The financial incentives and barriers to offering home-based modalities were also thoroughly reviewed by Oreopoulous and colleagues.

In this issue, a University of Toronto-based research group attempts to define the gaps in realizing homebased modalities [6]. Zhang and colleagues correctly introduce the rationale for promoting home-based therapies, including improvement in quality of life and cost-effectiveness. Further, they reinforce the importance of the multidisciplinary team in facilitating the timely initiation of the most appropriate renal replacement modality-essentially the reformulated integrated care concept. The fact that $61 \%$ of patients transitioned into a home-dialysis modality is a remarkable achievement by this team. Their focus, however, was to determine what predisposes people to modality choice.

Although retrospective in nature, some of the results were somewhat intuitive; home HD patients were younger, English-speaking (in a Canadian city) employed/active individuals. On the surface, one would speculate that the technical aspects of a home HD machine would be less threatening to the younger generation. We suspect that this is probably not the case-a 62-year-old is probably just as technology savvy as a 48-year-old. The more important distinction is probably employed versus retired individuals. Those who are working require a little more flexibility than those who are retired, and it just so happens that employed individuals are younger, hence the inherent issues with an observational, retrospective design. Zhang and colleagues, however, highlight important findings that require further study. Should we target retired and more seasoned individuals with various support strategies or should we just convince them that flexibility in their lives will afford them enjoyment?

The Zhang study has important limitations. The authors acknowledge that it is a retrospective study. It is not clear whether the rationale for selection was specifically documented at the time of modality decisions and/or whether a specific instrument was used to capture the reasons. We suspect that there was not, since the authors inform us that $39 \%$ did not specify a reason. It is more likely that the reason was never recorded and so was not available years later when charts were assessed for this study. Because this is such a high number of patients essentially "lost to follow up", the frequency distribution of the stated reasons may not be accurate.

There are also questions about the generalizability of these results to other jurisdictions. For example, there are places with a very ethnic demographic mix, low socio-economic status, and language and housing barriers that will operate to limit the pool of patients eligible for home dialysis. While it seems clear from the literature that many more patients are eligible for home dialysis than has been assumed in the past [79], the ability to transition them to home will vary from place to place.

The Zhang and colleagues article highlights some potentially important individual reasons for choosing a home- or non-home-based dialysis modality. Their conclusions, drawn from an observational and retrospective cohort, warrant very serious consideration, because simple interventions (perhaps by offering more social supports) may have a large individual and societal impact (greater quality of life and fewer resources required for it).

We would like to reaffirm our belief that the reformulated integrated care concept proposed by Mendelssohn and Pierratos [4] and recently restated by Oreopoulos and colleagues [5] is congruent with the political agenda of most governments and provides an ethical, patient-centered approach to care. The model focuses on timely referral and management of cardiac risk factors and comorbidities in an effort to slow the progression to end-stage renal disease. For suitable patients, it encourages and promotes home-based dialysis therapies (both home HD and PD) as well as pre-emptive live donor transplantation but does not force patients who are not suitable or not willing [10]. Most importantly, patients themselves are intimately 
involved in decision making throughout the continuum of their care.

\section{References}

1. Mendelssohn DC (2004) Empowerment of patient preference in dialysis modality selection. Am J Kidney Dis 43(5):930-932

2. The USRDS Dialysis Morbidity and Mortality Study: Wave 2 (1997) United States renal data system. Am J Kidney Dis 30(2 Suppl 1):S67-S85

3. Lameire N, Van Biesen W, Vanholder R (2000) The role of peritoneal dialysis as first modality in an integrative approach to patients with end-stage renal disease. Perit Dial Int 20(Suppl 2):S134-S141

4. Mendelssohn DC, Pierratos A (2002) Reformulating the integrated care concept for the new millenium. Peritoneal Dial Int 22:5-8
5. Oreopoulos DG, Thodis E, Passadakis P, Vargemezis V (2009) Home dialysis as a first option: a new paradigm. Int Urol Nephrol 41(3):595-605

6. Zhang A, Bargman JM, Lok CE, Porter EC, Mendez M, Oreopoulos DG et al (2010) Dialysis modality choices among chronic kidney disease patients: identifying the gaps to support patients on home-based therapies. Int Urol Nephrol. doi:10.1007/s11255-010-9793-9

7. Jager KJ, Korevaar JC, Dekker FW, Krediet RT, Boeschoten EW (2004) The effect of contraindications and patient preference on dialysis modality selection in ESRD patients in The Netherlands. Am J Kidney Dis 43(5):891-899

8. Mendelssohn DC, Mujais SK, Soroka SD, Brouillette J, Takano T, Barre PE et al (2009) A prospective evaluation of renal replacement therapy modality eligibility. Nephrol Dial Transpl 24(2):555-561

9. Oliver MJ, Quinn RR, Richardson EP, Kiss AJ, Lamping DL, Manns BJ (2007) Home care assistance and the utilization of peritoneal dialysis. Kidney Int 71(7):673-678

10. Mendelssohn DC (2009) Increasing pd utilization: should suitable patients be forced? Perit Dial Int 29(2):144-146 